\title{
The Application of Financial Technologies for Predictive and Visual Analytics
}

\author{
Alexander Y. Yap \\ Department of Business Information Systems and Analytics \\ North Carolina A\&T State University \\ Greensboro, North Carolina 27411, USA
}

\begin{abstract}
Fintech, or Financial Technology, is growing in popularity as financial services become highly integrated with backend information systems and technologies for end-consumer use. Technology that used to be in the background and used only by financial professionals are now available for end-users who need financial services at their fingertip, especially those who invest and trade ubiquitously. As more investors and traders manage their own stock portfolio without the help of human brokers, the need for predictive and visual financial analytics to manage a self-maintained financial portfolio is critical. There are a growing number of special services for investors and traders, who demand detailed analyses of their investments and financial derivatives. The objective of this paper is to contribute more teaching cases in financial analytics classes that involves stock trading. The paper examines how various services provide predictive financial analytics using data mining, intelligent algorithms, and visual analytics and have students in finance who manage their own simulated financial portfolio to use these Fintech tools to improve their stock trading strategies.
\end{abstract}

Keywords: Predictive analytics, Fintech, Financial Data Mining, Data Pattern Recognition, Stocks andOptions trading, Price analytics

\section{INTRODUCTION}

Due to the massive need to process raw financial and economic data in the global financial market such as daily stocks prices, volume of stocks traded, stock price fluctuations, and the movement of major stock indices, there is a growing need for new ways to generate both visual and textual knowledge representations, so that non-professional investors and traders can make more informed and intelligent investment and trading decisions in managing their own portfolios.

Knowledge representation is how information or data is represented to enable human beings to grasp data and information in meaningful terms. We sometimes think human knowledge is communicated mostly through textual information, but other types of knowledge are more effectively communicated visually in terms of graphs, pictorials, symbols, and images. Information in graphic or symbolic form is not only expressing what is being shown, but how it is being shown to improve the effectiveness and speed of human cognition. Text, numbers, graphs, animation, and symbols can all be combined in a rich form of knowledge representation to amplify human cognition, speed up the cognitive process, and enhance intelligent perception.

For investors and traders, how massive amounts of financial data is processed and presented in both textual and graphic form is very important for them when making daily buying and selling decisions. The math wizards of Wall Street often referred to as the "quants" (Crooks, Slayton, Burbridge (2011) and Zuckerman and Hope (2019), use mathematical algorithms (Deng, Wang, Dong, 2012) and fast super-computers (Kelly, 2012) to generate stock price predictions, and are able to process massive amounts of raw financial data and transform them into intelligent stock price predictions that can be read by both humans and machines. While these data can be presented in both text and visual representations, many investors and traders seem to be able to make more intelligent split-second decisions on the buying and selling of stocks based on easy-to-interpret visual data representations that they see on their screen such as "candlestick charts" (Chatterjee, 2019) ${ }^{\mathrm{i}}$.

As stock traders and investors have a very limited time window to analyze and intelligently digest financial data before they decide to buy or sell stocks and options, the software interface for financial analytics is critical for this particular end-user group. The main contribution of this paper is to determine the predictive analytics capabilities of financial technologies used to analyze stock price movements and display the predictive analytics in visual analytics form.

With the findings of this research, students interested in finance and investing will have a better grasp of how Fintech is used to predict stock price movements. 


\section{How Predictive and Visual Analytics are Applied in Trading Decisions}

The purpose of this research is to share three cases that we use for teaching financial technology in a financial information systems class. The class particularly focuses on using technology for stock trading, where students create their own simulated portfolio and use these information systems to make critical decisions on trading stocks and options. These Fintech websites have some basic free services that are enough for students to sample and use. And if the users of these websites want to use more of their features, then they pay for it.

The focus of these cases is on Predictive and Visual Analytics. For various Financial Technologies used in stock trading, predictive analytics is essentially embodied in the visual analytics representations. In this paper, when we discuss visual analytics, a large part of that already embodies predictive analytics. Investors and traders that rely on financial predictive analytics usepredictive visual analytics in the form of smart interactive charts that displays unique data patterns in graphic formats to predict short-term stock price movements. This is why many experienced traders always watch interactive charts on their screen for them to make short-term predictive decisions.

We propose the following conceptual framework on how predictive analytics is used in the financial trading decisions.

(1) Finding Unique Data Patterns - financial analytic applications track the movement of the price of a stock and determines unique patterns in the stock price movement for short-term predictions. Japanese candlestick patterns like Doji Stars, Harami, and Hammers, are visual tools that have been used in Japan by Japanese rice traders to predict the future rice prices (Nisson, 2001). In his article "Can a Machine Learning Model Predict the SP500 by Looking at Candlesticks", Filho (2019) discusses how machine learning can learn the more important candlestick patterns or the patterns that send strong predictive signals. He further discusses in his paper that machine learning should only be used when there are clear candlestick patterns forming that machines could learn from. In today's stock market, candlesticks are predominantly used by technical traders as a predictive visual analytics tool to determine when to buy or sell stocks.

While candlestick patterns are eastern methods for predicting stock price patterns, western countries also developed their own patterns for predicting stock prices. Woods (2019) discussedvisual patterns that have been used by western traders for decades like 'head and shoulder', 'cup and handle', 'flag', and 'triangle' patterns to predict where short term prices may be heading.

(2) Benchmarking Stock Price Movements - Intelligent algorithms allow analytics tomeasure the past prices of stock price movements. Stock prices go up and down due to market sentiments and emotions. As Wall Street analysts would say, there are two emotions on Wall Street - fear and greed. And stock prices and go up and down based on those two principles. So, the algorithms of predictive analytics keep track of the price range of stock movements, where it usually peaks and where it bottoms, and what the moving average price is. Prudent traders are patient to buy at the lower price range and sell at the higher price range. Bollinger Bands (Hayes, 2019) shows the moving upper and lower price ranges of a stock price base on standard deviation, and is displayed in visual charts. Bollinger Bands is a form of benchmark to show if the stock price is somewhere near the bottom or the top of its price range. Moving price averages for the last 22 trading (1 month, excluding weekends) days and 50 trading days ( 2 months, excluding weekends) are also tracked to benchmark whether stock prices are going above the past price averages. The volume of stocks shares traded on a daily basis is also an important benchmark. Volume is a great benchmark, because if the stock price goes up on a substantive volume then the price increase is usually more sustainable. If a stock price goes up with very little volume, the price can go down as quickly as it went up if the trade volume is low.

(3) Visual Analytics: a Necessary Front-end component of Predictive Financial Analytics-the traders and investors who trade in the financial markets need visual tools to make quick decisions and predictions due to the cognitive advantage of visual representations in presenting data and information more effectively (Zoss, 2013). While intelligent algorithms and data mining analytics works to produce predictive analytics, traders and investors who need to make quick split-second decisions to either buy or sell stocks would still need to rely heavily on visual analytics that embodies the predictive analytics generated by data mining and intelligent algorithms. Predictive analytics are fully integrated in the Visual Analytics for it to work for the end-user, the stock traders and investors (see Figure 1).See Appendices for all Figures.

\section{Fintech case 1:Stockfetcher.com - predictive analytics using visual and statistical patterns}


Stockfetcher.com functions like a data mining engine focused on finding unique visual and statistical patterns that stock traders consider as a signal to buy or sell stocks. The software looks at the movement of a stock's price, the volume of shares traded, and the market's perception on that particular stock. We can look at three examples out of hundreds of different patterns that this technology helps investors. In Figure 2, it finds a pattern called "Gap Up on Volume" and it has a definition of what that means. It says that the "stock opens more than $5 \%$ higher than the previous day and the volume of shares traded is $100 \%$ above the average volume traded." It then searches and identifies several stocks that meets this unique pattern.

In Figure 3, it identifies Symantec Corporation's stock as one stock that met this pattern whose price jumped from $\$ 22$ to $\$ 25$ or about a $13 \%$ increase. The price gap from $\$ 22$ to $\$ 25$ can be seen from the candlestick chart. And the average volume of shares traded is around 10 million shares from the chart, but on this particular day that it alerted investors, the volume of shares traded is 40 million shares and it is up $400 \%$. Again, the chart shows the visuals on the trade volume. Why is 'volume traded' an important statistics for traders and investors? It is because when traders see a stock price goes up with very low volume of shares traded, they feel that the price increase may not be sustainable. But a $400 \%$ increase in the volume of shares traded means that the price increase is much more sustainable because an incredible number of investors have bought into this event. So, this is an alert to buy the stock.

Another unique pattern this visual data mining technology looks for is called the 'Bollinger Upside Breakout'. It describes this pattern as a stock whose price have crossed the 'upper Bollinger' band (see Figure 4). Hayes (2019) defines a Bollinger band as "an upper and lower [price] band along the daily movements of the stock's price ... which is a measure of volatility using standard deviation, when the markets become more volatile the bands widen; during less volatile periods, the bands contract .. Bollinger bands was developed by the technical trader John Bollinger." For a visual chart example of a Bollinger band, see Figure 5.StockFetcher.com also has another price pattern called the 'Bollinger Downside Breakdown' that alerts investors if a stock price goes below the Bollinger band, then the price of that stock is about to break down to a much lower price. This is the opposite of the first pattern.

In Figure 5, StockFetcher.com identifies the Coca Cola stock that has this pattern at this given point in time. The Bollinger band in Figure 4 is depicted in the Blue lines as the upper and lower price limits in the price fluctuations based on past price standard deviations. The visual representation is helpful for traders as they can see how prices fluctuate between the upper and lower price bands. And the reason for this pattern as a 'buy alert' for investors is that Coca Cola's stock reaching a price above $\$ 52$ means it has breached the upper Bollinger band, or the previous upper standard deviation limit. What this means is that there is a bigger probability that the price will go much higher than the price limit of the current upper Bollinger band. Stock traders call this a 'break out' or a stock price running to a higher level.

StockFetcher.com claims their systems tracks and recognizes 125 unique stock price movement patterns that signals it is time to buy or sell, and alerts investors if these visual and statistical patterns are found by their data mining engine.

Case Analysis 1: Stockfetcher.com feature fits the conceptual framework about how predictive analytics are useful in stock trading. Stockfetcher.com use to search for stock price patterns; benchmark statistics like price range bands (Bollinger bands) and trading volume; and use visual analytics in the form of charts with predictive data. So this system meets all the three aspects of predictive analytics discussed in our conceptual framework.

\section{Fintech case 2: Maximum-pain.com - predictive analytics using future options contract price}

Traders in the stock market try to predict the future prices of stocks by using the money invested in future options contract. Maximum Pain (or Max Pain, in short) is a predictive concept to determine where the future price of a stock may be going based on the amount of money or investments traders and investors pour into stock options contracts. In today's stock market, there are options contracts expiring every Friday for most stocks. Before discussing Max Pain in detail, we want to discuss options briefly to give this concept the proper context.

Call options are future contracts that guarantee traders that they can purchase a stock at a future guaranteed price (or called a strike price). For example, if the current stock price of a company is $\$ 100$, and a trader bought a call option equivalent to 100 shares that expires in 3 months with a strike price of $\$ 115$ at a contract price of $\$ 2$ per share, then that trade is in effect making a bet that the stock will be higher that $\$ 117(\$ 115+\$ 2)$ after 3 months.

The trader is guaranteed that he can still buy the stock at the price of $\$ 115$ after 3 months even if the price goes up higher than $\$ 115$. The $\$ 2$ price is also called an "options premium" or a fee to party who issued that options contract. For a 100 shares equivalent, $\$ 2 /$ share $\mathrm{x} 100=\$ 200$, and this is the amount the trader pays for the premium call options 
contract. If after 3 months, the stock does not go up to $\$ 117$, the trader loses that $\$ 200$ he spent. However, if after 3 months, the stock price goes up to $\$ 127$, for example, then the trader gains $\$ 10 /$ share $(\$ 127-\$ 117=\$ 10)$. Since the call option is good for 100 shares, then $\$ 10$ per share $x 100=\$ 1000$. $\$ 1000$ is the profit of the trader who invested $\$ 200$ in the call options contract.

A Trader can also buy a Put option, which guarantees that the trader can sell a stock at a guaranteed price in the future. Let say a trader invested in a stock when it was $\$ 80$ per share and bought 100 shares $(\$ 80 /$ share $\mathrm{x} 100$ shares $=\$ 8,000$ invested), and the stock price has gone up to $\$ 210(\$ 210 \times 100=\$ 21,000)$. So, in paper, the trader has made a profit of $\$ 13,000$ ( $\$ 21,000-\$ 8000=\$ 13,000)$. The trader feels that it might go up some more and he does not want to sell the stock, but he wants to be protected if it goes down in the future. So, he purchases a Put Options contract with a strike price of $\$ 210$ that matures in 3 months and it cost him \$10/share premium to own this Put options contract. Considering the $\$ 10$ price of the option, his break-even price is $\$ 200$ (\$210-\$10). This gives him some peace of mind that he can still sell his stock at $\$ 210$ three months from now in case it goes down. This Put option cost the trader $\$ 1000(\$ 10 \mathrm{x}$ $100)$ to protect his profit. So, if the stock does indeed go down after 3 months to $\$ 140$, the trader is still able to sell it at a net price of $\$ 200$ and keeps a $\$ 12,000$ profit $(\$ 13,000-\$ 1000=\$ 12,000)$ instead of losing $\$ 6,000$ with the fall from $\$ 210$ to $\$ 140(\$ 21,000-\$ 14,000=\$ 6000)$. Although his initial profit was $\$ 13,000$, he paid $\$ 1000$ to guarantee that he still has $\$ 12000$ in profits after 3 months. If the stock goes up to $\$ 250$ in 3 months, the trader loses the $\$ 1000$ Put options premium as it expired worthless, but gains $\$ 4000$ (with the price going up from $\$ 210$ to $\$ 250$ ).

As can be seen from these examples, traders use call options and put options to leverage and hedge on future stock prices. Many traders do not even trade stocks, but just trade or buy and sell call and put options. Options traders usually have more expertise and experience than regular stock traders and they largely determine the value and price of options contracts based future uncertainties and the volatility of stock prices. Many of these options traders are institutional investors with a large amount of money invested and they use these options contracts to hedge against future price increases or decreases. Since the future options market are closely watched by stock market investors, the aggregate amount of money spent on options contracts is used as a predictive data and tool by many traders and investors about where the stock prices are going into the future.

The Max Pain strike price is the strike price at which the least amount of call and put options are paid out for that particular options expiration date. The predictive analytics model combines all the money invested in both call and put options and the Max Pain system determines the strike price where the least amount of options money is invested. The reason why the market feels this is where the future stock price is heading is because options traders are unwilling to pay a higher options premium for this strike price, and this means options traders foresee that the future price of the stock can indeed fall into this price range. Traders view max-pain strike price as the equilibrium level where stock prices might be heading.

The system Maximum-Pain.com determines the amount of money invested in both Call and Put options. Their systems takes all the data invested in options and creates a chart that shows how much money in invested in both Call options and Put options, and determines where the Max-Pain strike price is. In Figure 6, the chart shows red and green bars as put and call options investments, respectively. The yellow line is the max-pain strike price showing the total minimum dollar invested in both call and put options. These are the options contract invested in the stock of the company called Beyond Meat (BYND) and the Max Pain strike price was determined by the system during June 29, 2019 to be $\$ 152.50$ for Friday July 5, 2019. In Figure 7, the stock price of Beyond Meat closed at $\$ 152.63$ on July 5, 2019, which is about 0.13 cents away from the Max-Pain strike price. Max Pain is best used as a weekly predictor of where stocks may be heading by the end of the week when options expired every Friday.

While in this instance, Max Pain was able to predict the price on July 5, it was because there was no major news or events from June 29 to July 5 regarding this particular stock. Max Pain is more of a technical prediction and assumes no major fundamental changes in the company's finances (like bankruptcy or loss of a major customer) and no major event has occurred from the time the system makes a prediction to the date the prediction (like a war breaking out or a global crisis). So, Max Pain is used for very short-term technical predictions, possibly good for a week or two into the future.

Case Analysis 2: The concept of Max Pain is not limited to the Maximim-Pain.com website. The Max Pain calculation method is a mathematical model used in other websites as well. The analytics behind it is to "benchmark" the amount of investments in options contracts as a predictive statistics on where the future stock price is going.

And visual analytics is used to make visualize where future prices are going. So, this case clearly falls in our conceptual framework discussion. 


\section{Fintech case 3 -Stockconsultant.com-predictive analytics using past price fluctuations}

Stockconsultant.com is another provider of advance financial analytics that help traders make short term predictions as to where stock prices are moving based on statistical probability and past statistical and data patterns of stock price movements.

For example, if we look at the chart generated by StockConsultants.com for Tesla's stock (TSLA). They have generated pink and blue lines with corresponding prices (see Figure 8). Their analytics systems have identified these price points as critical based on past trading data. The pink lines are called 'resistance levels' while the blue lines are called 'support levels'. Tesla's stock has been on a decline for the past three months from the $\$ 300$ level to below $\$ 200$. And as the analytics has indicated in the chart, the price has found "support" at $\$ 183.96$, which is where the stock price has bounced back upwards. "Support" here means that at this price level, a lot of buyers came in to support the price and the sellers lost all power to bring the price down further. As the price moved up, the analytics system also found another price support level at $\$ 194.71$. So, this means that prices below the $\$ 200$ level is attractive to buyers of Tesla stocks. Their systems rates these support levels from a strength of 1 to 10, based on the volume of shares bought. And the support level at $\$ 183.96$ is rated at "5", while the support level at $\$ 194.71$ is rate at " 8 ". So as soon as buyers felt there was strong support at the $\$ 183$ level, it created a stronger buying pressure at the $\$ 194$ level, which pushed the stock price back up above the $\$ 200$ level. Based on past data, the financial analytics system also determined that there are resistance levels. Resistance levels are the opposite of Support levels. Resistance means that when the stock hits a resistance price level, it has a hard time breaking above that price range. As indicated in the chart, the Tesla stock tried to climb above \$227 twice. The first time it failed and lingered around \$214 - \$227. And as of this writing, it has actually succeeded in breaking the $\$ 227$ resistance level. So, if the Tesla stock must go up further, it will need to break the next resistance level which is at $\$ 242.77$ as indicated in the Stockconsultant.com chart. And if it does indeed succeed and go above the $\$ 242.77$ level, stock buyer's confidence will increase and the next resistance level at $\$ 271.88$, which has a strength of "10". Because Tesla has just recovered from a steep downturn, the upward recovery is predicted to face several levels of price resistance.

Stockconsultant.com financial analytics system also provides recommendations in a simplified language that is understood by stock traders. In Figure 9, it says that there is a "rally" in the Short term direction, but is "near overbought", because the stock has climbed from a $\$ 183$ - \$194 price range in early June to $\$ 233$ in the first week of July. So, the 'overbought' sign just means that the steep climb up in the stock price may taper off the stock's price increase further, and for the intermediate trend, the stock price may move 'sideways' according to the system's recommendation instead of going up or down. The financial analytics system then conclude in Figure 10, that the stock is $65 \%$ mildly bullish, which means that based on the price trend, the volume of stocks bought, and the $\$ 227$ price resistance being broken, the probability of the stock price going up some more has a slightly higher probability. Again, these are short term predictive suggestions that may reverse if new events and new data arises. However, by July 12, Tesla's stocks furthered climbed to $\$ 245$ as the rally continued, confirming the $65 \%$ bullish probability that the price from $\$ 233$ could still go up.

Case 3 Analysis: Stockconsultant.com covers all the three areas we discussed in the conceptual framework. Their system (1) searches for unique pattern using algorithms to determine whether stock prices will go up or go down in the near future, (2) they use predictive analytics to benchmark various price support and resistance levels, and (3) and they use visual analytics and dashboard gauges to translate those predictive analytics results into easy to understand visuals.

\section{Conclusion and summary}

In conclusion, several Financial Technology (Fintech) applications have been developed that can be used by students involved in stock trading to create their own predictive analytics strategies in assessing where certain stock prices may be heading in the short term. The paper explores only a few of these predictive Fintech applications, but there are several more that needs to be assessed. In the stock market, they say there is a 50-50 chance that stocks can either go up or down. So, if a predictive analytics systems can predict $65 \%$ or higher accuracy, then traders consider it as a useful tool. Everyone working in investments and Wall Street are always predicting where stocks, options, and futures are going, and more Fintech tools for analytics are now available for students to use freely.

Using intelligent systems that gather massive amounts of data from minute-to-minute stock price changes, the volume of stocks traded, the volume of stock options contract traded, these intelligent systems intelligently mine these data with algorithms to find patterns, calculate probabilities, and also convert it into better knowledge representations like intelligent visual analytics that recommends where traders may buy or sell stocks and options. 


\section{References}

Bruckhaus, T. (2007), The Business Impact of Predictive Analytics, Knowledge Discovery and Data Mining: Challenges and Realities, 114-138.

Chatterjee, K. (2019), Types of Candlestick Patterns Explained With Examples. Retrieved September 8, 2019 from https://www.skcapitalanalysis.com/candlestick-patterns-explained-with-examples/

Crooks, D., Slayton, J., and Burbridge, J. (2012), Information Technology and Financial Markets: Risk, Volatility, and the Quants. Information Systems for Global Financial Markets: Emerging Developments and Effects. Business Science Reference Publication, Hersheys PA, 1-18.

Deng, X., Wang, F., \& Dong, K. (2012), Algorithmic Trading Strategy Making: Algorithms and Applications. Information Systems for Global Financial Markets: Emerging Developments and Effects. Business Science Reference Publication, Hersheys PA, 55 - 72

Filho, M. (2019) Can a Machine Learning Model Predict the SP500 by Looking at Candlesticks. Retrieved September 8, 2019 from http://mariofilho.com/can-machine-learning-model-predict-the-sp500-by-looking-at-candlesticks/

Hayes, A. (2019), Bollinger Band Definition. Retrieved July 10, 2019 from https://www.investopedia.com/terms/b/bollingerbands.asp

Kelly, J. (2012). FPGA Speedup for Financial Network Models. Information Systems for Global Financial Markets: Emerging Developments and Effects. Business Science Reference Publication, Hersheys PA, 321368Maximum-pain.com (2019), Retrieved on June 10, 2019 from

maximum-pain.com/options/max-pain/

Nisson, S. (2001), Japanese Candlestick Charting Techniques, Second Edition, New York Institute of Finance.

Passera, S. and Haapio, H. (2013), The Quest for Clarity: How Visualization Improves the Usability and User Experience of Contracts. Innovative Approaches of Data Visualization and Visual Analytics. IGI-Global Publication, Hersheys PA, 191-217

Patterson, S. (2010) The Quants: How a New Breed of Math Whizzes Conquered Wall Street and Nearly Destroyed It, Crown Publishing, New York.

Stockconsultant.com (2019), Retrieved on June 10, 2019 from www.stockconsultant.com

Stockfetcher.com (2019), Retrieved on June 10, 2019 from www.stockfetcher.com

Schumaker, R. and Hsinchun, C. (2012), Predicting Stock Price Movement from Financial News Article.Information Systems for Global Financial Markets: Emerging Developments and Effects, Business Science Reference Publication, Hersheys PA 96-128

Watson, H. (2013), All about Analytics. International Journal of Business Intelligence Research, 4 (1), IGIPublication, Hersheys, PA. 13-28.

Wilson, I.A. (2013), The Evolution of the Massively Parallel Processing Database in Support of Visual Analytics. Managing Information Resources and Technology: Emerging Applications and Theories. IGI-Publications, Hersheys, PA. $212-237$

Woods, G. (2019), 10 Chart Patterns for Price Action Trading. Retrieved Sept. 8, 2019 from https://www.tradingsetupsreview.com/10-chart-patterns-price-action-trading/

Xiao, L. and Dasgupta, S. (2005) User Satisfaction with Web Portals: An Empirical Study.Web Systems Design and Online Consumer Behavior, Idea Group Publishing, 192-204.3

Zuckerman, G. and Hope, B. (2019) The Quants Run Wall Street Now, Wall Street Journal. Retrieved from September 5, 2019 from https://www.wsj.com/articles/the-quants-run-wall-street-now-1495389108

Zoss, A.M. (2013), Cognitive Processes and Traits Related to Graphic Comprehension. Innovative Approaches of Data Visualization and Visual Analytics. IGI-Global Publication, Hersheys PA, 94-110

\section{Appendices and Figures}

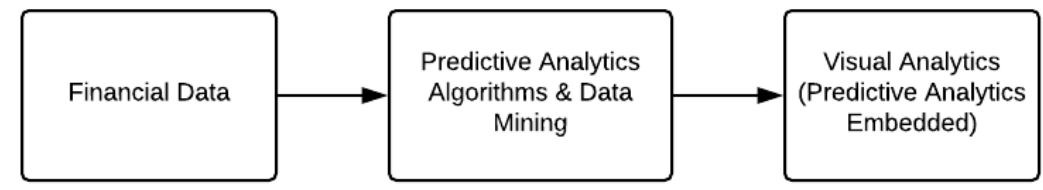

Figure 1. Using Algorithms and Data Mining, Predictive analytics process financial data to create benchmarks and look for patterns and then embeds the result in cognitive-enhancing visual analytics 


\begin{tabular}{|c|c|c|c|c|c|c|}
\hline StockFetcher.it] & Search & Examples & New Filter & Watchlists & Forums & Indicators \\
\hline New 52 Week Lows & & & Popular Examples & & \multirow{9}{*}{ E } & Filter Preview (edit) \\
\hline Gap Down On Volume & & & Popular Examples & 65 & & \multirow{9}{*}{$\begin{array}{l}\text { show stocks where open is more than } 5 \% \text { above close } 1 \text { day ago } \\
\text { and volume is more than } 100 \% \text { above average volume (30) } 1 \text { day ago } \\
\text { and draw MA(50) } \\
\text { and draw Ma(200) }\end{array}$} \\
\hline Gap Up On Volume & & & Popular Examples & 78 & & \\
\hline RSI Bearish Crossover & & & Popular Examples & & & \\
\hline MA 50/200 Bearish Death Cross & & & Popular Examples & & & \\
\hline Bollinger Downside Breakout & & & Popular Examples & & & \\
\hline CCl Crossed Below - 100 (Sell) & & & Popular Examples & & & \\
\hline RSI Bullish Crossover & & & Popular Examples & 50 & & \\
\hline MA 50/200 Bullish Golden Cross & & & Popular Examples & & & \\
\hline Bollinger Upside Breakout & & & Popular Examples & 29 & 2 & \\
\hline
\end{tabular}

Figure 2. Gap Up Volume Pattern

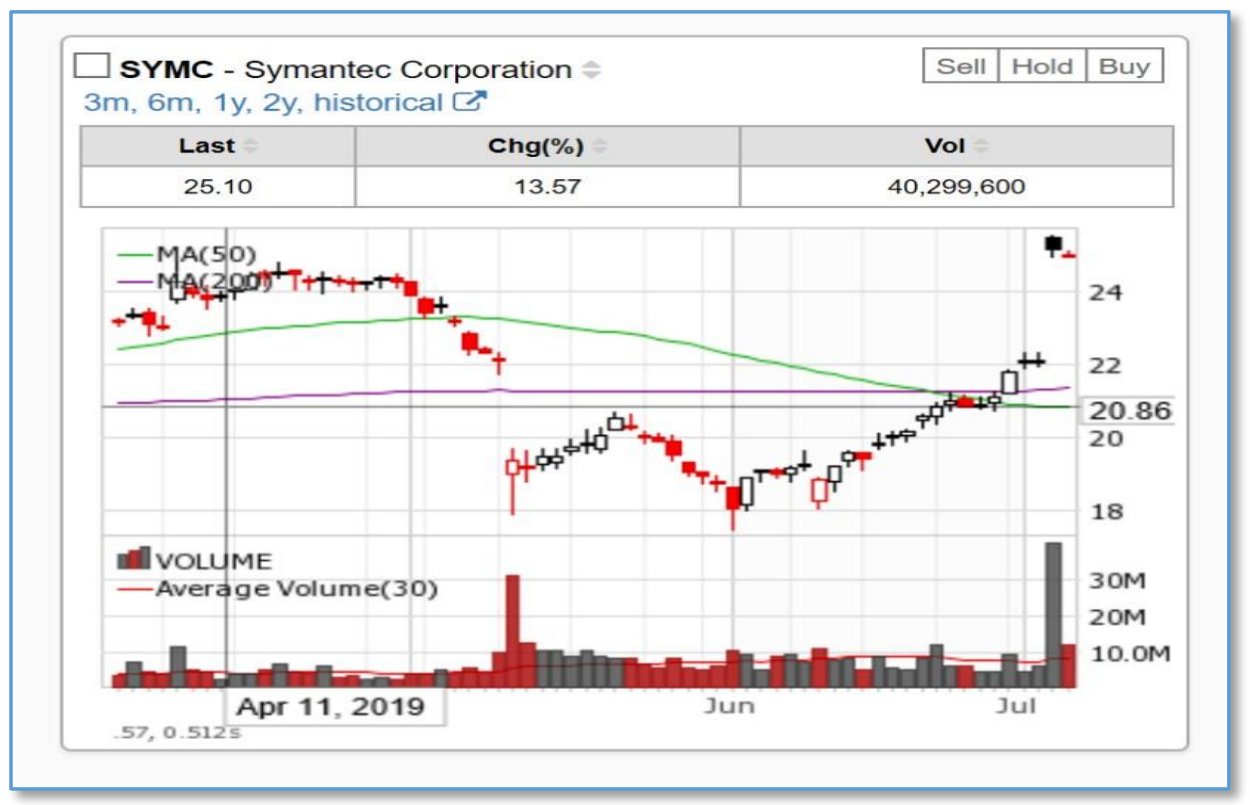

Figure 3. Example of a Gap up Volume Pattern using candlestick charts

\begin{tabular}{|c|c|c|c|c|c|c|c|}
\hline StockFetcher.It] & Search & Examples & New Filter & Watchlists & Forums & Join Now ! & Sign In - \\
\hline Gap Down On Volume & & & Popular Examples & & $\wedge$ & Filter Preview (edit) & \\
\hline Gap Up On Volume & & & Popular Examples & & 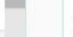 & \multirow{9}{*}{\multicolumn{2}{|c|}{ 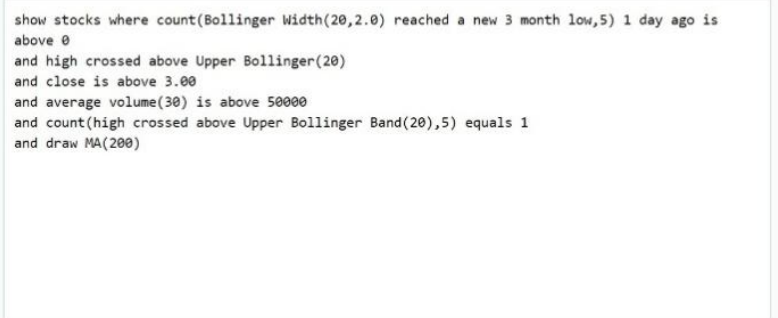 }} \\
\hline RSI Bearish Crossover & & & Popular Examples & & & & \\
\hline MA 50/200 Bearish Death Cross & & & Popular Examples & & & & \\
\hline Bollinger Downside Breakout & & & Popular Examples & & & & \\
\hline CCI Crossed Below -100 (Sell) & & & Popular Examples & & & & \\
\hline RSI Bullish Crossover & & & Popular Examples & 50 & & & \\
\hline MA 50/200 Bullish Golden Cross & & & Popular Examples & & & & \\
\hline Bollinger Upside Breakout & & & Popular Examples & 29 & & & \\
\hline $\mathrm{CCl}$ Crossed Above 100 (Buy) & & & Popular Examples & & & & \\
\hline
\end{tabular}

Figure 4. Bollinger Upside Breakout Pattern 


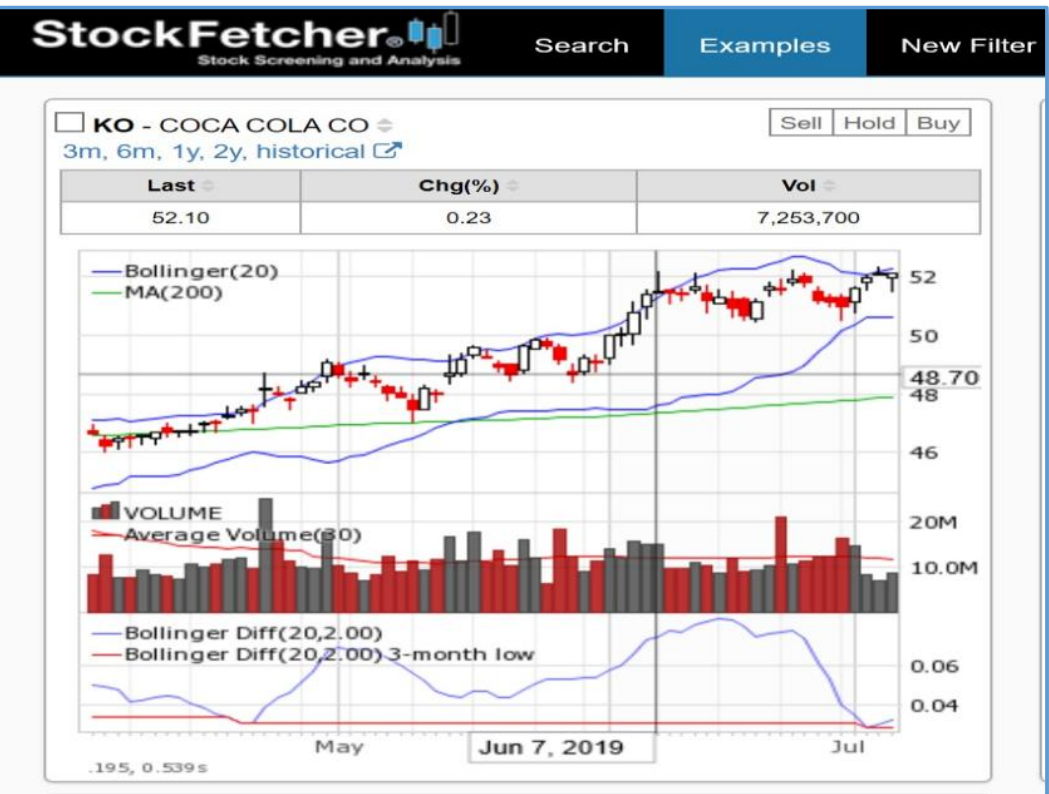

Figure 5. Coca Cola Stock hits the upper Bollinger Band at \$52 (Upper Blue Line)

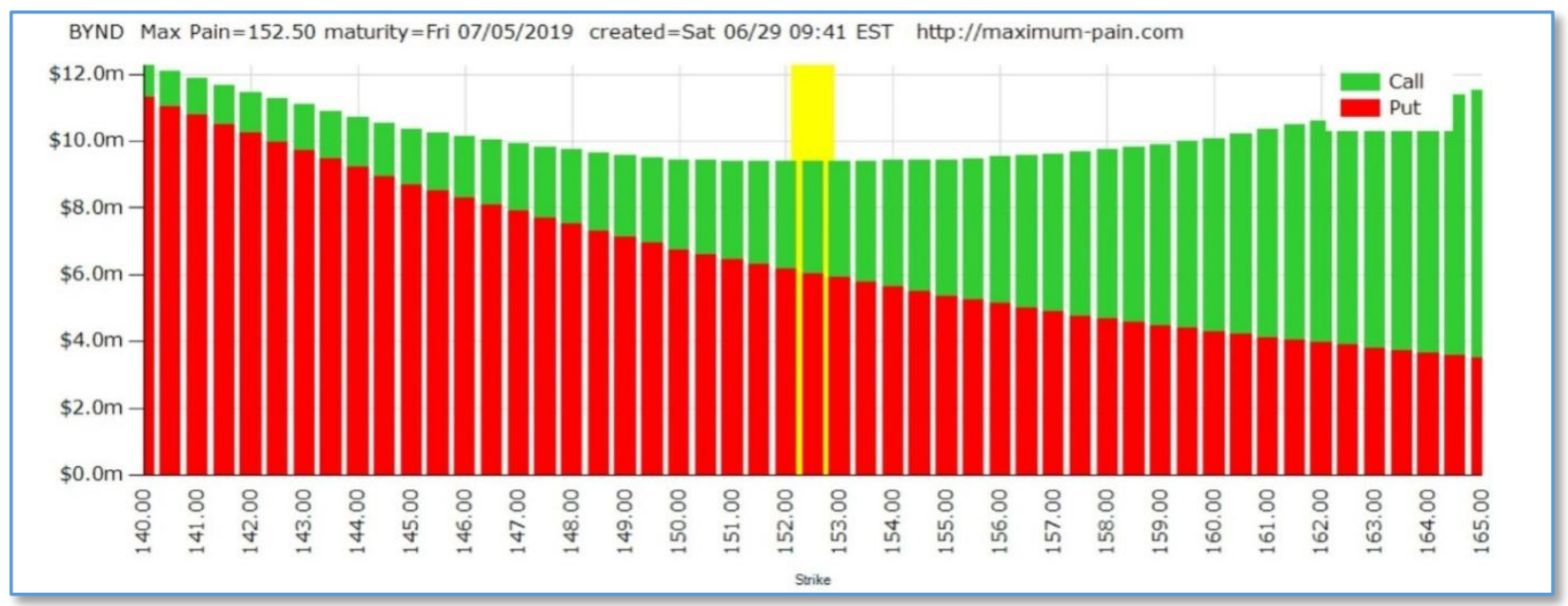

Figure 6. Max Pain Chart of the stock options of Beyond Meat for July 5, 2019 is $\$ 152.50$ and the forecast was created on June 29, 2019 or 7 days before. 


\section{Beyond Meat, Inc. (BYND)}

NasdaqGS - NasdaqGS Real Time Price. Currency in USD

\section{$152.63+1.13(+0.75 \%)$}

At close: July 5 4:00PM EDT

Summary Company Outlook NEW Chart Co

Figure 7. Beyond Meat stock price closed at $\$ 152.63$ or very near the Max Pain strike price of $\$ 152.50$.

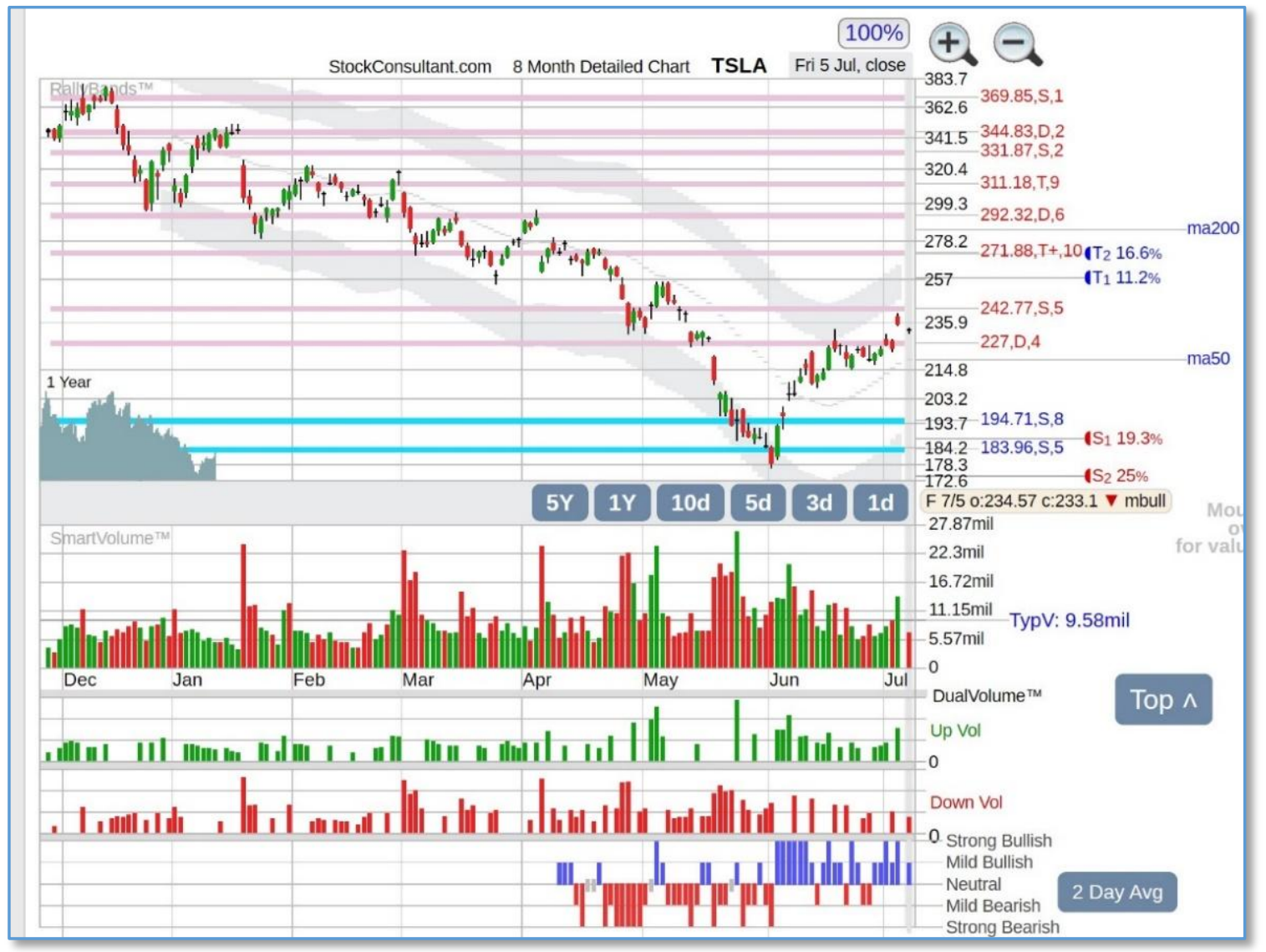

Figure 8. Visual chart identifying support levels (blue line) and resistance levels (red lines) 


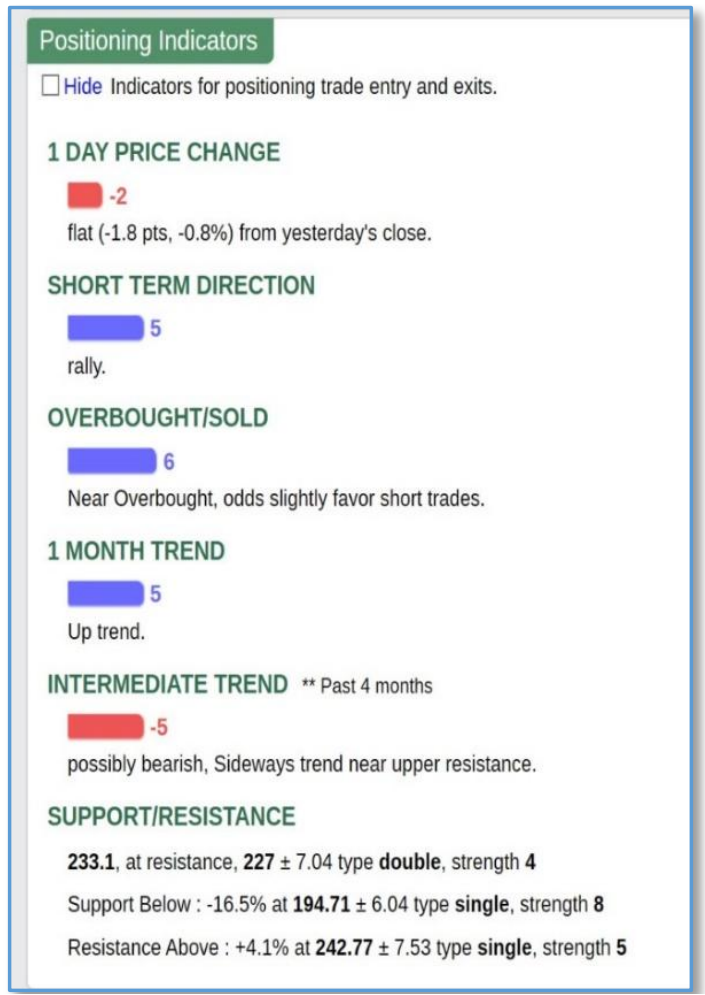

Figure 9. The data on stock price movements and algorithms are translated into a more simplified language that traders understand.

\section{Overall}

A summary of bullish and bearish indicators.

The overall bullish and bearish positioning and timing.

Use with trade quality for optimizing long and short entries.

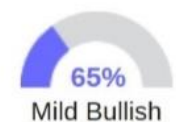

\section{BULLISH}

[Timing] Mild bullish 3 day candlestick pattern with Strong 3 day accumulation.

\section{BEARISH}

[Positioning] Intermediate trend possibly bearish, Sideways trend near upper resistance.

[Positioning] at resistance

Figure 10. Stockconsultant.com has a concluding statement regarding how 'bullish' or 'bearish' their predictive systems is with a probability number. In this case, their system view the stock as $65 \%$ bullish, therefore predicting a price increase in the short term.

${ }^{i}$ Candlestick charts are charts that use candle-like visuals to depict where a stock's price open and close on a trading day, and it also depicts the highest and lowest price of the day. 